Marquette University

e-Publications@Marquette

College of Nursing Faculty Research and

Publications

Nursing, College of

$5-1-2000$

Parenting a Second Time Around: An Ethnography of African American Grandmothers Parenting Grandchildren Due to Parental Cocaine Abuse

Kristin Haglund

Marquette University, kristin.haglund@marquette.edu

Accepted version. Journal of Family Nursing, Vol. 6, No. 2 (May 2000):120-135. DOI. (C) 2000 SAGE

Publications. Used with permission.

Kristin Haglund was affiliated with the Medical College of Wisconsin at the time of publication. 


\section{Parenting a Second Time Around: An Ethnography of African American Grandmothers Parenting Grandchildren Due to Parental Cocaine Abuse}

By Kristin Haglund

This study describes a group of six African American grandmothers parenting their grandchildren secondary to cocaine abuse on the part of the parents. It explores the manner in which such parenting affected the grandmothers' health. Data for this ethnography design were collected through participant observation, field notes, taped interviews, and supplementary data sources. The identification of cultural themes evolved from domain and taxonomic analyses. The themes_parenting a second time around, sacrifice, and God's presence in daily life-expressed aspects of the grandmothers' culture. The effects on health varied from none to exacerbation of chronic illnesses. The study results, and its picture of life from the grandmothers' perspectives, suggest areas of nursing assessment and intervention that otherwise might be left unexplored.

African American grandmothers are often portrayed in literature and popular culture as matriarchs, central stabilizing figures that hold a family together (Burton, 1992; Franklin, 1997). It often is assumed that a grandmother will naturally accept the role of parenting her grandchildren. However, this assumption represents a limited picture of the African American grandmother (Burton \& Dilworth-Anderson, 1991); urbanization, individualistic values, and changes in childbearing patterns and family structures might have rendered the grandmothers less willing to assume this role (Burton \& Bengtson, 1985). Today, many African American grandmothers desire a relationship with their grandchildren that still allows time for their own interests and self-development (Burton, 1992; Minkler \& Roe, 1993; Shore \& Hayslip, 1994); as a result, taking on the role of parenting grandchildren may be physically, emotionally, and economically exhausting. It also may elicit ambivalent feelings, especially if the role is assumed out of necessity, as often is the case when the grandchild's parent is abusing cocaine.

Parenting grandchildren in the wake of a parent's cocaine abuse may be a different experience than parenting as a result of parental unemployment, divorce, or teen parenthood. These grandmothers have the difficult task of caring for children who may have been prenatally exposed to drugs and to dysfunctional parenting, neglect, or abuse. As noted by several authors (Besharov, 1989; Koppleman \& Jones, 1989; O’Reilly \& Morrison, 1993), such children subsequently may have emotional, behavioral, or physical problems and special needs that 
present significant parenting challenges.

Additional challenges for these grandparents may include dealing with hostile, abusive persons who steal money or property to obtain drugs (Chychula \& Okore, 1990). The family members of the cocaine-abusing person witness the deterioration of their loved one and suffer the loss of this person. Thus, although the experience of parenting a grandchild may have positive aspects, it might also be a source of stress and distress in a grandmother's life. When parenting a grandchild is coupled with the parenthood of a cocaine abuser, the likelihood of stress and distress is increased (Turpin, 1993).

\section{Effects On Health While Parenting Grandchildren}

Studies on parenting grandparents, most of whom were grandmothers, have found positive and negative effects on the health of grandparents. Negative effects included complications of diabetes and arthritis, perceptions of decreased health, increased psychological distress, and increased health risk behaviors such as alcohol and cigarette use (Burton, 1992; Kelly \& Damato, 1995; Minkler \& Roe, 1993). Grandparents parenting grandchildren have reported feelings of depression and anxiety (Burton, 1992) and exhaustion (Minkler \& Roe, 1993). They also reported feelings of anger and helplessness amid their inability to help their children become responsible parents (O'Reilly \& Morrison, 1993) and resentment toward their children for not accepting parental responsibilities (Robinson, 1989; Shore \& Hayslip, 1994). Furthermore, some of these grandparents reported significantly decreased satisfaction with grandparenting and decreased overall well-being (Shore \& Hayslip, 1994).

The effects on these grandparents' health were attributed to a number of stressors, including financial drain, overwhelming responsibilities, lack of time to attend to personal needs, social isolation, lack of child care, and observation of the cocaine-abusing child's deterioration (Burton, 1992; Kelly \& Damato, 1995; Minkler \& Roe, 1993). Finally, grandparents felt stress because of fears that their own health would suffer and result in death or an incapacitating illness and subsequent inability to care for the grandchildren (Kelly, 1993; Shore \& Hayslip 1994). Some grandparents in these studies may have downplayed the negative effects of surrogate parenting on their health for fear of losing custody of the children (Minkler \& Roe, 1993).

Alternatively, fear of losing the grandchildren led some grandparents to improve their health by quitting smoking, losing weight, and getting medical care (Minkler \& Roe, 1993). Other positive effects included feelings of purpose and usefulness, self-satisfaction, and the experience of love from the children (Burton, 1992; Kelly \& Damato, 1995). Finally, some grandparents reported improved health amid reduced contact with their cocaine-abusing child, knowledge that 
the grandchildren were safe, increased activity with less time to worry, and coming to terms with the drug abuse of their child (Minkler \& Roe, 1993).

The phenomenon of parenting of a grandchild holds many complexities. Many grandparents would rather not assume parental responsibility for their grandchildren, yet when the children must be removed from parental custody because of drug abuse, most grandparents accept the children. Although parenting grandchildren may lead to adverse effects on health, some of its aspects may lead to improvements. This study was done to examine the phenomenon of parenting grandchildren from the grandmothers' perspectives and to specifically investigate how parenting grandchildren affected the grandmothers' health.

\section{Method}

\section{Sample}

This ethnographic study included families recruited from the case-loads of public health nurses in a large midwestern city. The sample was chosen according to who provided the richest data (Germain, 1993) and who was representative of the culture (Leininger, 1985). The primary informants were African American grandmothers who had parented their grandchildren for at least 1 year because of cocaine addiction of the children's mothers. All the informants had legal custody of the children. All of the names used in this report are pseudonyms. Four women were primary informants.

Three to seven visits were made with all the primary informants except Ms. Lewis, whose lack of time permitted only one visit. Each visit was an average of 1.5 hours; the visits lasted from 15 minutes to 5 hours.

Ophelia Johnson was 44, married, and parenting three grandchildren, ages 4, 5, and 7 years. Ms. Johnson had custody of these children for 5 years. Martha Brown, 56 and divorced, was parenting 5 grandchildren, ages 1, 4, 6, 7, and 11 years. She had custody of these children for 11 years. Angela Jones, also 56, was a widow, parenting 4 grandchildren ages 3 months, 1, 3, and 16 years. She had custody of these children for 9 years. Finally, Nancy Lewis was 41, divorced, parenting two grandchildren ages 1 and 7 years in addition to her own three minor children and also providing care for her chronically ill father. Ms. Lewis had custody of the children for 7 years. Except for Ms. Lewis, all the women had at least two chronic illnesses, including asthma, arthritis, scoliosis, degenerative joint disease, obesity, sarcoidosis, hypertension, or diabetes.

Those who were not grandmothers parenting grandchildren but were in a similar situation (such as a great-grandmother and a great-aunt), or others who were intimate with the 
grandmothers and whose experiences were necessary to develop an understanding of the culture (Schulte, 1992), were included as supplementary informants.

One home visit was conducted with Abigail Adams, a 57-year-old widow who suffered from chronic headaches. She had parented her great-grandchildren, ages 4 months and 4 years, for the past 4 years. One home visit and interview was conducted with Lavonda Wilson, a 60-year-old widow with hypertension. Ms. Wilson was helping her daughter, who had legal custody, parent her great-niece. In addition, informal interactions occurred during home visits between the researcher and many of the grandchildren, some of the cocaine-abusing mothers, the grandmothers' other adult children, and family friends.

\section{Design}

This study was designed as a small-scale ethnography with a specific focus (Leininger, 1985). An ethnography uses at least three types of data collection: participant-observation, in-depth interviewing, and supplementary data sources (Germain, 1993). Participant-observation involved observation of the grandmothers and their families within their home environments. Field experiences ranged from 15 minutes to 5 hours, with a total of 37 hours spent in direct observation.

The home interviews were conducted through a repertoire of query strategies (Agar, 1980). As cultural understanding grew, more specific questions were asked. When the situation was appropriate, interviews were taped, although Ms. Lewis and Ms. Adams refused to be audiotaped. During other visits, the researcher simply stayed beside the grandmother, her grandchildren, and a variety of other people, but taping was precluded as the grandmother divided her attentions between the needs of her family and the researcher. Some field notes were taken; then, immediately following the field experiences, complete notes, including verbatim quotations, were generated. Twelve 1-hour interviews with four informants were taped and transcribed.

Supplementary data sources included observations during a support group meeting for parenting grandmothers; personal documents shared by the informants, including letters, photographs, and writings; newspaper articles; and a television special on grandparents parenting grandchildren. A fieldwork journal contained a record of field experiences, researchers' responses and ideas, and a logistics log. The journal was used to identify personal biases and as part of the audit trail (Lincoln \& Guba, 1985).

\section{Data Analysis}

Data analysis occurred concurrently with data collection. Transcribed interviews, field

\section{Haglund 4}


notes, supplementary data, and the fieldwork journal were analyzed by domain and taxonomic analyses (Spradley, 1979). A domain is a symbolic, limited category of knowledge that includes phrases and words semantically related to a cover term. The data were searched for repeated phrases, ideas, or experiences, grouped into domains, and labeled with a cover term. In this analysis, 15 domains were identified: setting, characteristics of grandmothers, characteristics of mothers, characteristics of grandchildren, health promotion practices, chronic illnesses, sources of illness, effects on health secondary to parenting, events leading up to placement, ways to help mom get treatment, reasons for taking the children, personal sacrifice, sources of support, love, and faith in God.

The taxonomic analysis involved categorizing the items in a domain to identify subsets of cultural knowledge. Taxonomies were developed in seven of the identified domains. For example, the domain called effects on health was categorized into negative and positive effects. Finally, the identification of cultural themes evolved out of the domain and taxonomic analyses, repeated reading of the field journal and transcripts, and relistening to the audiotapes. A cultural theme is a cognitive principle, assumed or explicit, that recurs in more than one domain and connects different subsystems of a culture (Spradley, 1979). The identified domains were divided into four themes: health effects, parenting a second time around, sacrifice, and God's presence in daily life. Identified themes were tested in the field and confirmed by informant agreement. Characteristics of the grandchildren were not reported in this article.

\section{Rigor}

Rigor in qualitative designs can be measured in terms of credibility, transferability, dependability, and confirmability (Lincoln \& Guba, 1985).

Credibility is the faithful depiction of the informants' lived experiences that would be recognizable to themselves, as opposed to the verification of a preconception of those events. Credibility was achieved through participant observation, prolonged engagement, and a search for clarification and confirmation from informants.

Transferability is the capacity to transfer the conclusions to another setting. Thick descriptions and verbatim quotations were presented so that a person using the research could judge the appropriateness of transferring the study findings to another group.

Dependability is achieved when a different researcher is able to reach similar conclusions using the researcher's perspective, raw data, and analytical documents.

Finally, confirmability refers to the maintenance of neutrality and the prevention of personal bias influence on the research. Bias was controlled through the use of a reflexive journal, 
peer review, consultation with expert researchers, and confirmation from informants.

\section{Results}

The effects on the grandmothers' health were varied, but in general, the informants spent little time discussing their own health. They often made comments such as "doing pretty good" and then approached a different topic.

\section{Health Effects}

The women had a variety of chronic illnesses, including hypertension, arthritis, scoliosis, sarcoidosis, asthma, obesity, diabetes, degenerative joint disease, and headaches. The reported parenting effects on these problems ranged from none to persistent aggravation.

Ophelia Johnson, who had scoliosis and arthritis and needed hip replacement surgery, said,

It's hard, because by me being disabled, I have back problems and leg problems. Sometimes I can hardly get up to take care of them, but regardless of how much pain I be in...I got to get up. But I got to have an operation for an artificial hip to replace that cup. That's another thing. I want to take the operation so I can better my leg. But I can't take it because I talked to my doctor. He's talking about 6 to 7 weeks, maybe to a couple of months of not being able to walk. Who's going to take care of the kids? I don't have anybody who can take care of my grandkids.

Parenting of grandchildren had a definite effect on Mrs. Johnson's health, as it caused her to postpone her surgery. Other participants denied that specific health problems or exacerbation of chronic diseases were related to the children, yet later, they did report health complaints. Angela Jones denied that caring for the children had any negative effects on her diabetes or arthritis. However, she said that her blood sugar had been running high because of concern that her daughter would be killed by the drug-abusing people with whom she associated. Other grandmothers also reported that they worried about the safety of their drug-abusing child.

Exhaustion and stress were the most often cited health problems. Abigail Adams was fatigued from sleepless nights with her 4-month-old great-granddaughter Andrea and from chasing her 4-year-old great-granddaughter Annie during the day. The infant was on an apnea monitor, which required someone familiar with the equipment and competent in infant CPR to be with her at all times. This limited childcare to family members only.

Andrea cried at night until she was picked up, then fell asleep in her great-grandmother's arms. Because she awoke when returned to the crib, Abigail slept in a chair holding the baby. Abigail sometimes napped during the day but regretted it "because then things get away from 
me." In response to the question of effects on her health, she stated that she did not have much time to think about the subject. Yet, she reported feeling very tired and said, "I'm too old to have these little kids. Pretty soon I will need someone to take care of me."

To manage their chronic illnesses and to maintain their health, the grandmothers practiced a variety of behaviors, including dietary measures such as decreases in salt intake, consumption

of fruit, vitamins and herbs, and fasting; abstinence from cigarette and alcohol use; relaxation in a hot bath or reading; exercise through play with the grandchildren and through walking; consumption of prescription medication and maintenance of preventive health care such as mammograms, checkups, and Pap tests; searches for support from people with similar problems; viewership of talk shows; and finally, through personal activities such as singing, praying, and maintaining interests outside the home.

Some grandmothers did report positive benefits on their emotional health due to parenting their grandchildren. They reported that they experienced positive well-being from feeling and expressing love. They stated that they enjoyed time with their grandchildren and that they were happy to get to know them intimately. Finally, they reported that the knowledge that the children were in a safe, stable environment, rather than with their mothers or in foster care, provided relief.

\section{Parenting a Second Time Around}

The women in this study described themselves as hardworking. They had raised their own children largely as single parents due to divorce, spousal alcoholism or drug abuse, death, or abandonment. All the women worked outside the home while raising their children. Lavonda Wilson said,

I raised five children by myself because my husband died young. I raised my children up, and I just raised them, I guess. l'd get up, take my kids to school and my grandchildren. Drop them off, everybody, and go on to my job. If you know you got a family to raise, there's no husband around, you're going to raise [the children] if you want to do it. You can do anything that you want to do, all you got to do is make up your mind that you want to do it and you can do it.

Each of the informants had similar experiences leading to the placements of their grandchildren. The natural mothers had custody of their children at birth, but the parenting situation deteriorated because of the mothers' drug use. For a period of time, the grandmothers and other family members tried to help their daughters abstain from drugs and resume appropriate parenting of their children. Some families rented the mother an apartment, allowed her to live with family members in town, or sent her out of town to another relative's home. Some practiced tough love, talking, or confrontation, whereas others provided food or money to help 
support the children. They left the children with the cocaine-abusing mothers for a period of time, hoping that the responsibilities of motherhood would preclude the drug abuse. They also attempted to put the cocaine-abusing women out of the house, letting them hit rock bottom, and they threatened to take away parental rights.

In the end, the families' attempts failed. The women continued to use drugs, and the caretaking of their children deteriorated. Child abuse and neglect, such as leaving the children home alone unsupervised, not providing food for the children, spending the family's money on drugs, leaving the children at the homes of relatives and failing to return to get them, and incarceration led to the placement of the children with their grandmothers. Opehila Johnson explained how her grandchildren came to live with her:

My oldest daughter got started using cocaine, and she started abusing the children. She was living with my mother in an upstairs apartment, but she kept leaving the children on my mother. She'd just leave them and tell my mother that she's going to the store, and she wouldn't come back. She did this repeatedly. We had been warning her about it; she just kept on, kept on doing it. She'd beat her kids. She wouldn't take care of the kids. She'd go off and come back and wouldn't have any money. So the last time she did it, she had went off like 5 days and then came back. So after the third day, my mother called me and she told me. She says, "Ophelia you're going to have to come and get the kids. We're going to have to do something." I told her, I said, "Where's Vicki at, where's the kids at?" She said, "Vicki been gone; I just didn't want to tell you she been gone for days." And so I went over there and got them. When I went over there and got them, I said, well, I'm going to do her the same way that other people do. I love her, but I want to do this for her health, and called social services. They came in that day and they talked to my mother and they talked to me, and we told them that, you know, I love my daughter but it's not fair to the children. So the social service stepped in, and then that's how I ended up with the kids. I've had them like for 5 years now.

After a period of time, Child Protective Services and the court system were involved with all the families, and the grandmothers received legal custody of the children. The grandmothers stated that although they loved their daughters, they ultimately chose to protect their grandchildren. As Angela Jones said, “I still love her. I stand by her as much as I can. I can't abide by her mistreating the kids, because they didn't ask to be born and somebody's got to take care of them." The grandmothers ultimately accepted parental responsibility for the children because of love for the children and for their daughters, a sense of family responsibility, an aversion toward foster care, and to protect the children.

Acceptance of the grandchildren began the experience of parenting a second time around. Parenting the grandchildren was a long-term commitment, vastly different than a child's visit to grandma's house. These children were with their grandmothers for years, many since infancy.

Over time, some came to think of their grandmothers as their mothers and their birth mothers as a 
friend or playmate. This phenomenon was evident during a home visit with Angela Jones. As Angela's 1-year-old grandson's nose ran, she handed him some tissue and said, "Go by your mama and get your nose cleaned." The child walked back and forth from Kim, his mother, to Angela, finally stopping by Angela. Kim said, "He thinks that she's his mother. I have a hard time getting him to come by me." This experience was echoed by Ophelia Johnson, who said, "When she's [the children's mother] got her head together, she'll run and play with them. That's what they like about being around her, it's like being with another kid." Thus, the experience of parenting a second time represented a commitment to the grandchildren.

\section{Sacrifice}

The theme of personal sacrifice, integral to parenting, was evident in the lives of the informants. "Eighteen years of sacrifice, then you want to enjoy yourself, but here comes the grandbaby," a participant at a support group for parenting grandparents said. A common sacrifice involved the grandmothers' abandoning or postponing long-term plans, activities, and dreams. They expressed the feeling that they should have time to pursue their own interests after their own children were grown.

Ophelia Johnson had plans to go to school and to spend more time with her recently retired husband. She said,

I've asked God why. I know you are not supposed to question, but I just have to ask. ...Iwas going to school for secretary work when I got the grandchildren. I had to stop then because I couldn't concentrate with them being so little. I was getting ready to start into LPN, but that got cut out, and I'm taking care of kids again. I imagine a lot of other grandmas feel the same way; you just can't get your life together....You think at this time in my life, I'm still young enough to enjoy life, can't go when I want to go, I got to get up to be sending kids to school, taking them to the doctors and washing clothes.

Ms. Johnson made sacrifices in her education and in her relationship with her husband, and other participants experienced sacrifices in personal relationships. For example, Martha Brown wanted to spend more time with her elderly mother in Mississippi but was not able to see her as often or as long as she felt was needed because of obligations to the grandchildren.

The women also reported anger and resentment in response to the sacrifices. They reported anger with their daughters for rejecting their parental responsibilities and that their grandchildren were not experiencing true parent-child relationships. Angela Jones explained,

Children are supposed to be with their mothers. Grandmothers love them and see after them, but the place of the kids is with their mothers. Kids shouldn't grow up without knowing their mother and father, doesn't matter if their mother and father are not together. 
They were also angry with the paternal families for not being involved with the children emotionally or financially. Nancy Lewis explained,

I do resent the mother and the father and the father's family for not taking care of the baby. They only want to see the kids on their birthdays to give them gifts or to see them and say how big they are, but do not want to make any contributions to their life.

For the most part, the grandmothers were solely responsible for the majority of work and expense involved in taking care of their grandchildren.

\section{God's Presence in Daily Lives}

The women expressed the conviction that God existed and was active in their daily lives. They frequently made spontaneous remarks about their relationship with God. God's presence in daily life represented a cultural theme because it appeared to permeate the grandmothers' lives. Martha Brown said it simply: "I am a very spiritually minded lady, and I believe highly in God. I believe this is how God has my life fated so I won't be alone."

God's presence also appeared to be a source of strength and support for the women to persevere in spite of difficulties. Nancy Lewis stated that she "would not have made it without faith." Ophelia Johnson said, "Sometimes I just want to give up; I have to pray and ask God to give me strength." Martha Brown identified a lack of social support that was filled by assistance from God. She said,

Well, my children, I talk to them, but sometimes I be having problems and I be wanting to talk to them and [they say] "ah Mama, we ain't got time." "I don't want to hear that right now." Well, see then, I don't have nowhere to go and turn to. With God in my life, I can lock my door and I can talk to God about it. I never hear it again, and it's worked out and don't nobody know it but me and God.

Most informants were active in their churches in a variety of ways, including ushering, teaching Sunday school, participating in the church choir, sending the grandchildren to Sunday school, and regularly attending services.

\section{Discussion}

This study captures only a small portion of a rich culture, yet it provides a picture of life from the grandmothers' perspectives. Although the findings may not be accurate for all African American grandmothers parenting their grandchildren, they do suggest areas for assessment that could yield important information about a woman's health, lifestyle, and family.

Ethnographic studies reflect the phenomenon as it was experienced during a period of time and under certain conditions. The results of this study might not be replicated as women's 
experiences and perceptions change. Nonetheless, thick descriptions of the women's experiences created an opportunity for the reader to determine the application of the findings.

Limited time was spent in the field, and a White female nurse, who was 13 years the junior of the youngest informant, conducted the study. Although a concerted effort was made to present a faithful account of the informants' experiences, this report may be biased by the researcher's interpretations. Observations and themes were verified by the informants during the study, thus increasing the credibility of this account.

Many people feel it is a grandmother's duty to take responsibility for her grandchildren when the parents no longer provide adequate care. It is not unusual for children to live with their grandparents; in fact, in the last census, approximately 3.2 million children lived with their grandparents or other relatives (U.S. Bureau of the Census, 1991). Thus, because it is not unusual, a woman may not volunteer that she is parenting her grandchildren. She also may be reticent to divulge this information because she is parenting amid her child's substance abuse.

Nurses must be sensitive to the possibility that their clients are parenting grandchildren. It is important for them to ask the women who lives with them and for whom they provide care. As reported, some grandmothers deny that their parenting responsibilities adversely affect their health. They may attribute suspicious blood sugars or high blood pressure to age or ascribe exacerbated respiratory conditions to the weather. Nurses working with parenting grandmothers may help them by exploring the effects on their health. This process may help the grandmothers achieve insights into their health and may facilitate discovery of methods to ameliorate negative effects.

Alternatively, exploring the effects of parenting grandchildren can identify benefits that might help develop health promotion practices and interventions. Knowledge of positive effects from the situation might aid the grandmothers in stressful times. Also, women in this study reported a key coping mechanism: the knowledge that others shared their life situation.

Accordingly, nurses working with these families might help them by informing them that they are not alone.

In addition, some grandmothers may appreciate referrals to a sensitive mental health care provider or to a local support group for parenting grandmothers, for parents of cocaine-affected children or children with special needs, or for relatives of substance abusers.

Further research is needed to identify ways to support grandparents who are compelled to parent their grandchildren. Future studies also should investigate the grandchildren's experiences when their grandparents assume parental responsibility for them.

Parenting grandchildren is not unusual and may become more common as states institute Haglund 11 
welfare reform. A recent article in The New York Times (DeParle, 1999) reported that in the welfare reform state of Wisconsin, increasing numbers of children are being placed with their grandmothers amid their mother's substance abuse problems, work schedules, or lack of money.

As identified in this study, parenting grandchildren is not easy and is not always desired by grandparents. Yet, for many children in need of placement outside their parents' custody, grandparents often are the best alternative. Without grandparents, many of these children would be placed in foster care or in institutions or would fend for themselves. The men and women who take in their grandchildren provide an opportunity for the grandchildren to thrive within the comfort of their own families. They also relieve the community of the responsibility and expense for care in institutions or in foster settings.

Current welfare reform programs require recipients to work as a condition of receiving benefits. Grandmothers who assume parental responsibility for their grandchildren and who require assistance should be exempt from these work requirements. Public policy should guarantee parenting grandparents financial assistance for basic living expenses such as health care, food, clothing, personal care items, and day care. These assistance programs must be publicized and readily accessible: "Welfare policy reforms should be undertaken to ensure that grandparent caregivers are supported, rather than penalized, for the critical role they are playing in raising some of the nation's most vulnerable children" (Minkler \& Fuller-Thomson, 1999, p. 1388).

Grandparents require and deserve support for maintenance of their own, and their grandchildren's, health and well-being. Supporting grandparents in these efforts is a worthwhile investment for the community and the children.

\section{Biography}

Kristin Haglund, R.N., M.S.N., is the program administrator of the Milwaukee Adolescent Health Program, Medical College of Wisconsin, Department of Pediatrics, Milwaukee. She is currently enrolled in the Nursing Ph.D. program at the University of Wisconsin-Milwaukee. Her research interests include women's health issues, particularly reproductive issues, and adolescent health issues such as sexual abstinence, risk behaviors, and access to health care. Recent publications include (with S. Matson) "Relationship Between Scholastic and Sexual Behavior and Reading Level in Adolescent Females," in Clinical Pediatrics (in press).

\section{References}

Agar, M. (1980). The professional stranger. San Diego, CA: Academic.

Haglund 12 
Besharov, D. (1989). The children of crack. Public Welfare, 47, 6-11.

Burton, L. (1992). Black grandparents rearing children of drug-addicted parents: Stressors, outcomes and social services needs. The Gerontologist, 32(6), 744-751.

Burton, L., \& Bengtson, V. L. (1985). Black grandmothers: Issues of timing and continuity of roles. In V. I. Bengtson \& J. F. Robertson (Eds.), Grandparenthood (pp. 61-77). Beverly Hills, CA: Sage.

Burton, L., \& Dilworth-Anderson, P. (1991). The intergenerational family roles of aged black Americans. Marriage and Family Review, 16(3/4), 311-330.

Chychula, N., \& Okore, C. (1990). The cocaine epidemic: A comprehensive review of use abuse and dependence. Nurse Practitioner, 15(7), 31-39.

DeParle, J. (1999, February 21). As welfare rolls shrink, load on relatives grows. The New York Times, pp. 1, 20.

Franklin, D. (1997). Ensuring inequality: The structural transformation of the African American family. New York: Oxford University Press.

Germain, C. (1993). Ethnography: The method. In P. Munhall \& C. Oiler Boyd (Eds.), Nursing research: A qualitative perspective (pp. 237-268). New York: National League for Nursing.

Kelly, S. (1993). Caregiver stress in grandparents raising grandchildren. Image, 25(4), 331-337.

Kelly, S., \& Damato, E. (1995). Grandparents as primary caregivers. Maternal Child Nursing Journal, 20, 326-332.

Koppleman, J., \& Jones, J. M. (1989). Crack: It's destroying fragile low-income families. Public Welfare, 47, 13-15.

Leininger, M. (1985). Ethnography and ethnonursing: Models and modes of qualitative data analysis. In M. Leininger (Ed.), Qualitative research methods in nursing (pp. 33-71). Orlando, FL: Grune \& Stratton.

Lincoln, Y., \& Guba, E. (1985). Naturalistic inquiry. Beverly Hills, CA: Sage.

Minkler, M., \& Fuller-Thomson, E. (1999). The health of grandparents raising grandchildren: Results of a national study. American Journal of Public Health, 89(9), 1384-1389.

Minkler, M., \& Roe, K. (1993). Grandmothers who care. Newbury Park, CA: Sage.

O’Reilly, E., \& Morrison, M. (1993). Grandparent-headed families: New therapeutic challenges. Child Psychiatry and Human Development, 23(3), 147-159.

Robinson, L. (1989). Grandparenting: Intergenerational love and hate. Journal of American Academy of Psychoanalysis, 17(3), 483-491.

Schulte, J. (1992). Finding ways to create connections among communities: Ethnography of urban public health nurses. Doctoral dissertation, University of Colorado. 
Shore, R., \& Hayslip, B. (1994). Custodial grandparenting: Implications for children's development. In A. Gottfried \& A. Gottfried (Eds.), Redefining families implications for children's development (pp. 171-218). New York: Plenum.

Spradley, J. (1979). The ethnographic interview. New York: Holt, Rinehart \& Winston. Turpin, S. (1993). Moral support for grandparents who care. American Journal of Nursing, 93, 52-56.

U.S. Bureau of the Census (1991). Current population reports: Marital status and living arrangements, March 1990 (Series P-20 No. 450). Washington, DC: Author. 